\title{
Space-Time Evolution Laws of Zonal Disintegration in Deep Underground Caves Based on Coordination Deformation between the Bolt Body and Surrounding Rock
}

\author{
Yuan-xiang Yu $\mathbb{D}^{1},{ }^{1}$ Zhi-xun Xie, ${ }^{1}$ and Bao-ping Chen $\mathbb{D}^{2}$ \\ ${ }^{1}$ School of Civil Engineering, Xi'an University of Science and Technology, Shaanxi 710054, China \\ ${ }^{2}$ Dalian University of Technology, No. 2, Linggong Road, Ganjingzi District, Dalian 116024, China \\ Correspondence should be addressed to Bao-ping Chen; 326398381@qq.com
}

Received 19 August 2020; Revised 15 December 2020; Accepted 27 February 2021; Published 5 May 2021

Academic Editor: Junhong Yuan

Copyright (C) 2021 Yuan-xiang Yu et al. This is an open access article distributed under the Creative Commons Attribution License, which permits unrestricted use, distribution, and reproduction in any medium, provided the original work is properly cited.

Zonal disintegration refers to the special phenomenon whereby fractured zones and intact zones appear alternately in deep-buried surrounding rocks under high stress conditions, which are different from that of the shallow rock mass. Because the divisional rupture law in engineering practice is closely related to the force characteristics of the bolt body, this paper analyzed stress distribution rules of the same bolt body at different times and that of different bolt bodies at the same time in the case of zonal disintegration based on coordination deformation between the bolt body and surrounding rock. The nonlinear rheological mechanics model of rock mass on the elastic-plastic interface under the maximum support pressure was established. It puts forward the theoretical calculation formula about the mechanics criterion and breakdown moment of the zonal disintegration. Using the mechanics model of interaction between a bolt and the surrounding rock, the distribution locations along the bolt body of the anchor neutral points and its maximum axial forces were discussed with the multiple theoretical neutral points. Furthermore, the location and width of each fracture zone were back analyzed. The results show that the rock mass on the elasticplastic interface of the surrounding rock has a significant creep effect after the excavation of the deep underground cave. While maximum deviator stress of the rock mass is more than its long-term strength, the rock mass will fracture along a radial direction and come into the fractured zone. The multiple redistribution of the surrounding rock stress will generate alternate distribution phenomena of the fractured zone and intact zone. Meanwhile, the distribution regularity of the peaks and troughs interval of the displacement of surrounding rock leads to multiple neutral points along the anchor length direction. The computed results of zonal disintegration through the back analysis can reflect the actual space-time evolution laws of zonal disintegration in deep underground caves.

\section{Introduction}

Since the twenty-first century, the development and utilization of deep rock mass engineering has been the most active research direction in the field of civil engineering. A large number of deep rock mass engineering projects, with depths of more than $1000 \mathrm{~m}$, such as mine roadways, mountain traffic tunnels, water diversion tunnels, nuclear waste disposal wells, and oil combat readiness storage projects, are being built successfully. According to incomplete statistics, there have been 100 metal mines with depths of more than $1000 \mathrm{~m}$ built in foreign countries, predominantly in South Africa and Russia. In China, the mining depth of many mines has also exceeded $1000 \mathrm{~m}$ and it is expected that many mines will reach depths between 1000 and $1500 \mathrm{~m}$ in the next 20 years. The maximum excavation depth of Zhongnanshan highway tunnel in Qinling is approximately $1600 \mathrm{~m}$ and that of the right line of Liutongzhai railway tunnel, which is under construction, is approximately $1400 \mathrm{~m}$. In addition, the water diversion 
tunnel in Jinping II hydropower station lies in $2600 \mathrm{~m}$ underground, and the depth of Jintan gas underground storage in Jiangsu Province is also over $1000 \mathrm{~m}$ depth.

The occurrence environment of deep rock mass engineering is generally characterized by "three highs," namely, high ground stress, high ground temperature, and high-pore water pressure as well as strong artificial disturbance. The surrounding rock shows a significant time effect and leads to many engineering disasters such as zonal disintegration, rock burst, and extruding deformation $[1,2]$. Among these disasters, the zonal disintegration of surrounding rock is typical of deep rock mass engineering and has attracted great attention from experts and scholars in the field of rock mechanics engineering, both in China and abroad. In the 1980s, Shemyakin found the phenomenon of "zonal rupture" of surrounding rock by resistivity meter in deep Маяк mine, as shown in Figure 1(a); Fang et al. [3] also observed the objective natural phenomenon of zonal disintegration, as shown in Figure 1(b), through field monitoring of a deep roadway surrounding rock in Chinese Jinchuan nickel mine.

In order to understand the formation mechanism and distribution law of zonal disintegration, domestic and foreign experts have conducted a considerable amount of research in this field. In foreign countries, the authors in [4] thought that the mechanism of fracture of deep roadway surrounding rock under unloading conditions is similar to the formation of the penetrating crack of the test specimen under lateral pressure conditions; the authors in [5] studied the deformation failure of the defective medium and the zonal disintegration of the surrounding rock in a deep roadway using non-Euclidean geometry; Metlov et al. [6] analyzed the zonal rock failure of the surrounding rock based on a nonequilibrium thermodynamics view; Mirenkov [7] pointed out that the shear stress around the hole increased at the position of $o$ times excavation radius; and Qi et al. [8] established the strain gradient equation for the zonal disintegration of surrounding rock in deep underground caves. In China, Bai [9] first discovered a very interesting engineering problem, the zonal disintegration of surrounding rock, by field monitoring the stress state of the bolt body. Subsequently, the authors in $[10,11]$ carried out a considerable amount of pioneering research on zonal disintegration. In recent years, mechanics and instability criterion [12-15] of the zonal disintegration of surrounding rock in deep roadways have been studied and numerical simulation tests of the zonal disintegration under different working conditions have been carried out [16-18]. The evolution law of the zonal disintegration under the condition of different hole shapes, loading methods, and characteristic parameters of surrounding rock has also been researched through similar material model tests [11, 19-22]. In addition, the time effect problem of the zonal disintegration has been thoroughly discussed in [23-25].

In conclusion, despite a series of research achievements on zonal disintegration obtained using on-site monitoring, model tests, theoretical analysis, and numerical simulation, this extremely complex rock engineering problem, which is closely related to space and time, remains the subject of many research questions regarding the mechanism and spatiotemporal evolution law of zonal disintegration. The full-length anchoring bolt is widely used as an effective active support technology for the surrounding rock of a deep cave. Although the stress and strain of surrounding rock are distributed alternately in waves and troughs, as pointed out in the literature $[3,20,21]$, and the actual stress state of the pull-pressure alternation was emphasized in [8] on the condition of zonal disintegration, research still neglects the idea that the basic law of zonal disintegration may be back analyzed according to the stress state of the bolt body. In this paper, the authors first establish the nonlinear rheological mechanical model of the rock mass on the elastoplastic interface of the surrounding rock, put forward the mechanics fracture criterion for the rock mass, and determine the fracture zone quantities as well as its formation moment. Second, the mechanical model to describe interaction between the surrounding rock and the bolt body on the condition of zonal disintegration will be established. A new approach for determining the location and width of each fracture zone is given in line with the principle and the mechanical model of coordinated deformation of bolt and surrounding rock. Finally, one engineering case study is presented to demonstrate the effectiveness, accuracy, and applicability of the proposed method for the zonal disintegration.

\section{Analysis of the Fracture Process of Surrounding Rock in a Deep Cave}

In the initial stage of the cave excavation, the second redistribution of surrounding rock stress occurs. Meanwhile, the maximum deviatoric stress originates from the difference between the tangential stress and the radial stress of the cave, which makes the deformation of surrounding rock develop into an elastic-plastic state and controls the steady state of the deep cave [19]. On account of the interior wall of the cave, a free surface, the surrounding rock produces lateral tensile expansion only towards the inside cave under the action of tangential maximum support pressure. On condition that the tensile deformation of surrounding rock reaches its ultimate strain, the first fractured zone, that is, pseudo-free surface, will arise in the surface area of the cave wall [26]. The first fractured zone appears impossibly after the surrounding rock stress is released because the level of ground stress is usually low. For a deep rock mass under high ground stress, the outer boundary of the first fractured zone generated after the stress is released is equivalent of a new excavation boundary. Thus, the surrounding rock stress is redistributed again. The surrounding rock stress is released again, and the second fractured zone comes into being in case the new ground stress meets the failure criteria of the rock mass [27]. Thus, in this way, the phenomenon of zonal disintegration will disappear until the maximum radial of the surrounding rock strain under the action of tangential maximum support pressure is lower than its ultimate tensile strain [10]. Ultimately, zonal disintegration in a deep underground cave is generated, as depicted in Figure 2. 


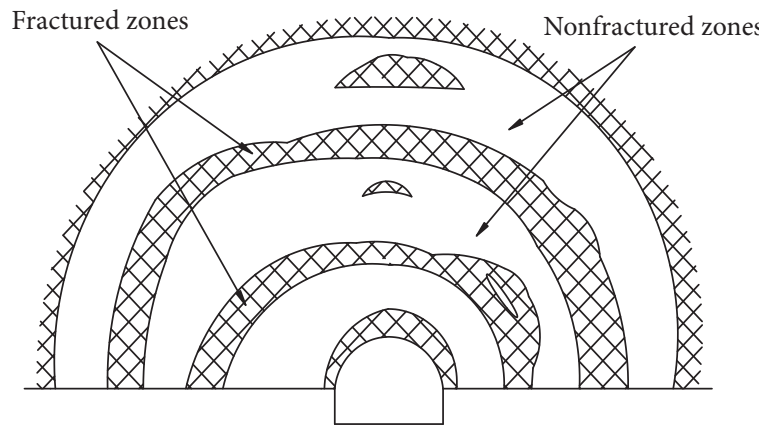

(a)

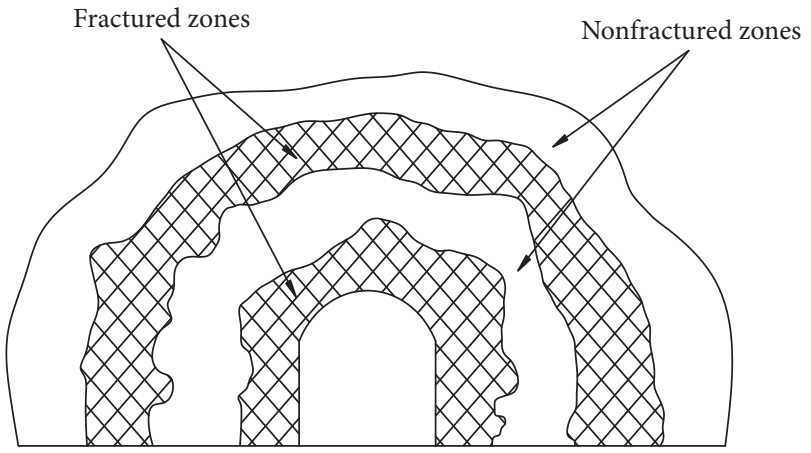

(b)

Figure 1: Measurement results of zonal disintegration in tunnels in deep mines: (a) zonal disintegration phenomenon in Russia's Mask mine; (b) zonal disintegration phenomenon in Chinese Jinchuan nickel mine.

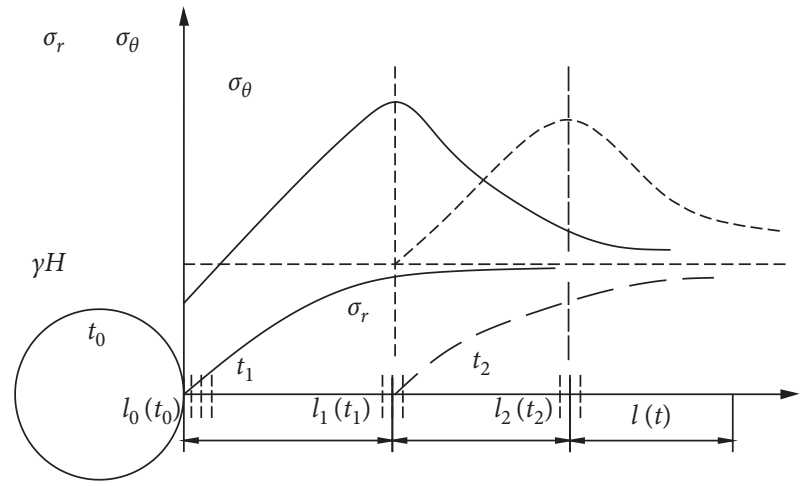

Figure 2: Analysis of zonal disintegration development.

\section{Analysis of Deformation Characteristics between Surrounding Rock and the Bolt Body}

3.1. Coordination Deformation Laws between Surrounding Rock and the Bolt Body under Conditions of Continuous Deformation. In general, the surrounding rock is subjected to continuous elastic-plastic deformation and even failure after the excavation of the cave, and it develops into the elastoplastic zone and fractured zone accordingly. The rock mass in each deformation zone has a different corresponding radial displacement rate, which leads to the objective phenomenon that the closer to the wall of the cave, the bigger the radial displacement rate of the surrounding rock. A section of the bolt body near the excavation face of the cave tends to prevent rock mass in the fractured zone from moving to the cave, where the surface produces negative friction pointing to the cave. Because the rock mass deformation rate in the elastic-plastic zone is lower than that in the fractured zone, some positive friction pointing to the deep surrounding rock is generated on the surface of the other section of bolt body under the pullout action of the previous bolt body. The interface between the positive friction and negative friction is called the neutral point of the bolt body, on which the friction and displacement of the bolt body relative to the surrounding rock are zero and the axial tension is maximized. The displacement of surrounding rock in different depths and the internal force of the bolt body regularities of distribution are shown in Figure 3 [28].

\subsection{Law of the Coordinated Deformation of the Surrounding} Rock Bolt Body in the Case of Zonal Disintegration. As mentioned previously, zonal disintegration will take place in the surrounding rock of the just-excavated cave under certain mechanical conditions. In accordance with the coordinated deformation principle of surrounding rock and the bolt body, the distribution of the friction resistance on the anchor surface varying with time and space is shown in Figure 4 .

The procession of zonal disintegration is a progressive repeated destruction process, which is closely associated with time and space, as can be seen in Figures 2 and 4 . The coordinated deformation process between surrounding rock and the bolt body includes the following stages:

(1) The first fractured zone comes into being after the rock mass near the cave surface has fractured at time $t_{0}$. The secondary distribution of surrounding rock stress occurs afterwards. A set of reverse friction resistance is distributed on the surface of the $l_{0}$ section of the bolt body, which is in a tensile state.

(2) The second fractured zone takes shape after the rock mass on the elastic-plastic interface of the secondary stress distribution has fractured at time $t_{1}$. The third distribution of surrounding rock stress occurs soon afterwards. A set of reverse frictional resistance is distributed on the surface of the $l_{1}$ section of the bolt body, which is in a tensile state. The bolt body of this section has the tendency of elongation which extrudes the $l_{0}$ section of the bolt body and moves it towards the cave. Meanwhile, the surrounding rock around the $l_{0}$ section of the bolt body will prevent that from moving to interior of the cave. Thus, some positive frictional resistance is distributed on the surface of the $l_{0}$ section of the bolt body, which is in a pressed status.

(3) Similarly, the third fractured zone takes shape after the rock mass on the elastic-plastic interface of the 


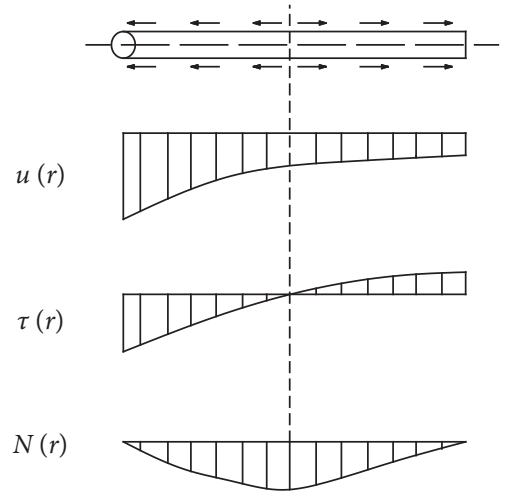

Figure 3: Distribution law of surrounding rock displacement and internal force of anchor bolt body.

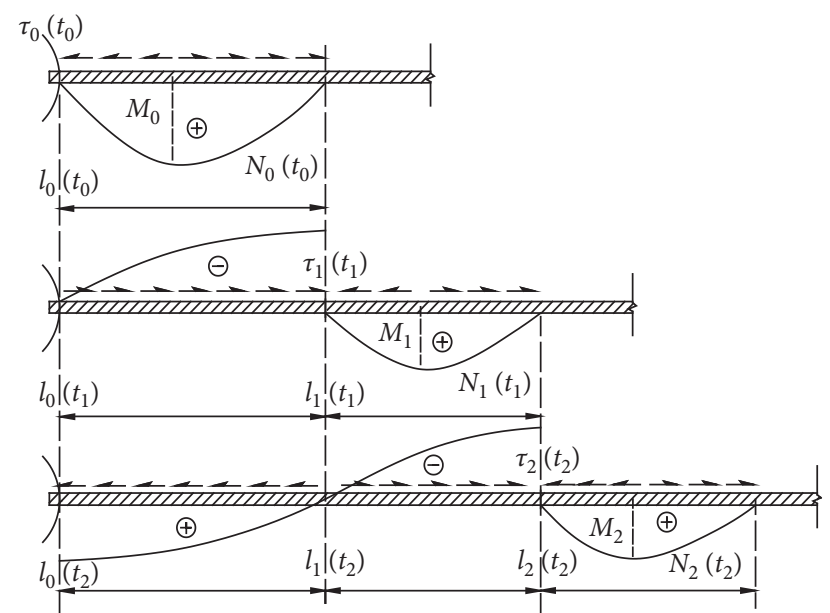

FIGURE 4: Bolt stress distribution at different times after supporting the tunnel.

third stress distribution has fractured at time $t_{2}$. The fourth distribution of surrounding rock stress occurs soon afterwards. The $l_{2}$ section of the bolt body, acted on by a set of reverse frictional resistance, is in a tensile state. It is known from the above analysis that the $l_{2}$ section of the bolt body is acted on by some frictional resistance pointing to the exterior of the cave. Therefore, it generates compressive deformation because it is in a pressed state. Due to the continuity of the bolt body, the $l_{0}$ section of the bolt body tends to displace towards the exterior of the cave which is prevented by the surrounding rock around the $l_{0}$ section of the bolt body and some negative frictional resistance is distributed on the surface of that bolt body, which is in a tensile status.

It is worth mentioning that Figure 4 also obviously indicates that there is always a stress state of tensionpressure alternation for the same bolt body at different times or for the different bolt bodies at the same time under the condition of zonal disintegration, which has been strongly verified by field measurements and laboratory tests. The tension-pressure alternating phenomenon of a certain section of the bolt body in surrounding rock with zonal disintegration was monitored in Quantai mine by Qi et al. [8], as shown in Figure 5. In addition, the radial strain of the surrounding rock in the deep cave is distributed with alternate peaks and troughs, varying in wave, which is also shown in Figure 6 [25].

Based on the geological mechanics model test of deep rock zonal disintegration, the authors in [20] pointed out that the radial displacement curve of the surrounding rock distributes with alternating peaks and troughs; the peak part of the surrounding rock with displacement maximum is the fractured zone, and the trough part of the surrounding rock with displacement minimum is the nonfractured zone, as shown in Figure 7.

The stress state of the full-column anchor bolt laid out in the surrounding rock presents a distribution law of the alternating tension and pressure due to the fluctuant change in the surrounding rock radial displacement curve with peaks and troughs, as is consistent with the stress distribution law of the bolt body at different moments or different sections of the bolt body, as illustrated in Figure 4 .

\section{Analysis of the Rheological Properties of Surrounding Rock after Deep Cave Excavation}

4.1. Deviatoric Stress Maximum Calculation Acted on the Rock Mass of the Elastoplastic Interface in Surrounding Rock. The surrounding rock of the cave is regarded as an ideal elastoplastic medium with continuous, homogeneous, and isotropic characteristics as well as remarkable creep behavior. The deformation of the surrounding rock can be simplified as an engineering problem of plane strain, while the axial length of the cave is much larger than its transverse width.

When the $(k+1)$-th fractured zone takes shape, the location under the support maximum pressure of surrounding rock is a new elastoplastic interface on which the radial horizontal stress $\sigma_{r k}^{p}$, tangential vertical stress $\sigma_{\theta k}^{p}$, and axial horizontal stress $\sigma_{z k}^{p}$ correspond to the minimum principal stress $\sigma_{3}$, maximum principal stress $\sigma_{1}$, and intermediate principal stress $\sigma_{2}$, which can be written as

$$
\sigma_{r k}^{p}<\sigma_{z k}^{p}<\sigma_{\theta k}^{p}
$$

where $k$ belongs to the natural number such as 0,1 , and 2 .

The deviator stress maximum on the elastic-plastic interface between the tangential direction and radial direction can be calculated as follows [29, 30]:

$$
\begin{aligned}
M & =\sigma_{\theta k}^{p}-\sigma_{r k}^{p} \\
& =\left(p_{k}+c \cdot \cot \varphi\right)\left(\frac{2 \sin \varphi}{1-\sin \varphi}\right)\left(\frac{R_{p k}^{e}}{R_{s(k-1)}^{e}}\right)^{(2 \sin \varphi / 1-\sin \varphi)},
\end{aligned}
$$

where $R_{s(k-1)}^{e}$ is the outer diameter of the $k$-th fractured zone, which is equal to the $(k+1)$-th excavation radius. In case of $k=0, R_{s(-1)}^{e}$ symbolizes the corresponding design excavation 


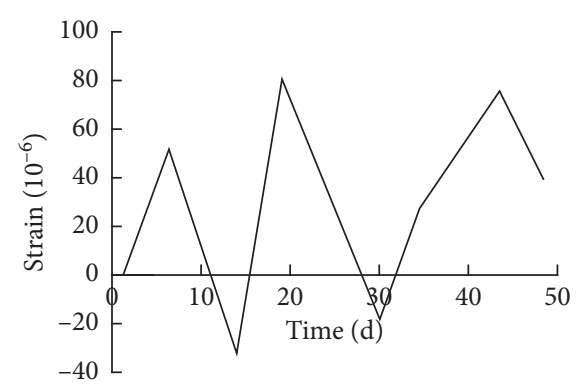

FIgURE 5: The tensile-compressive strain alternate distribution of the bolt body.

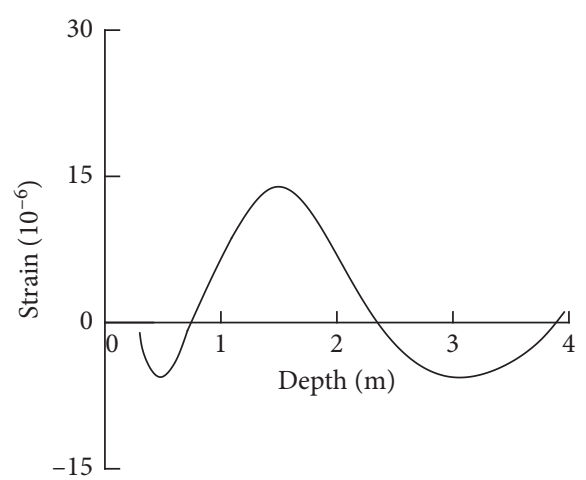

Figure 6: Measured in situ results of tensile-compressive strains distributed periodically in surrounding rock.

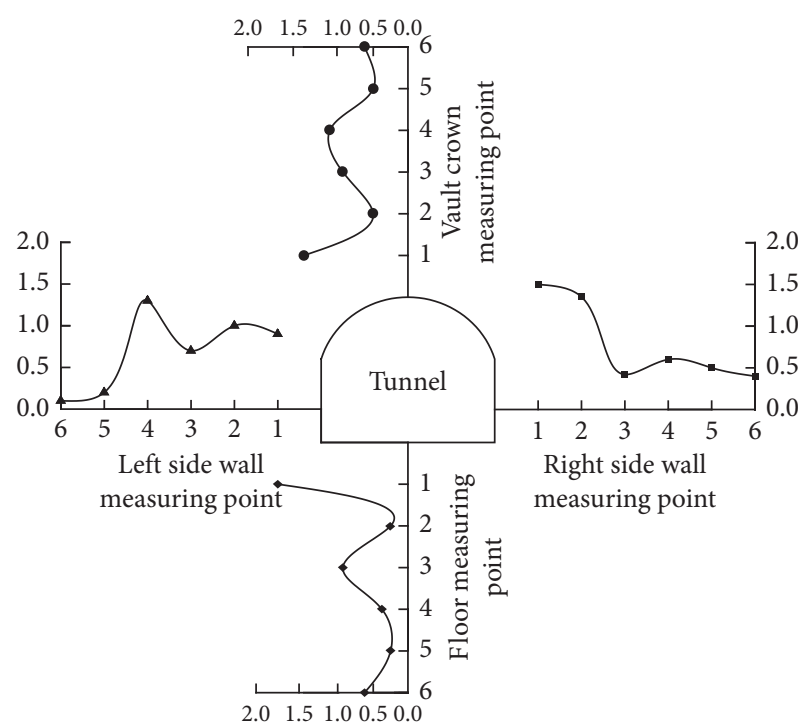

FIGURE 7: Changing curves of radial displacements for model cavern.

radius whose value is $R_{0}$ and $R_{p k}^{e}$ is the $(k+1)$-th plastic zone outer diameter that occurs after the $(k+1)$-th fracture or excavation of the surrounding rock.

Considering the dilation and expansion of the surrounding rock cracks during the stress redistribution, the mechanical properties of the surrounding rock will deteriorate continuously, and the effective cohesion and internal friction angle can be approximated as

$$
\left\{\begin{array}{l}
c=m c_{0}, \\
\varphi=n \varphi_{0},
\end{array}\right.
$$

where $c_{0}$ and $\varphi_{0}$ are the initial cohesive force and initial internal friction angle of original rock, respectively, and $m$ and $n$ are strength reduction factors, with ranges from 0.2 to 0.8 . The support reaction force acted on the interior surface of the cave loaded by bolt or on the interior surface elastoplastic interface due to the expansion deformation of the fractured zone can be computed with the following formula [31]:

$$
p_{k}=2 \tau_{s} \ln \left(\frac{R_{s(k-1)}^{e}}{R_{s(k-1)}^{i}}\right),
$$

where $R_{s(k-1)}^{i}$ is the inner diameter of the $k$-th fractured zone of the surrounding rock and $\tau_{s}$ is the residual shear strength of surrounding rock, which can be determined by the following formula [32]:

$$
\tau_{s}=\tau_{p}-c,
$$

where $\tau_{p}$ is the maximum of the shear strength.

It is necessary to point out that the support counterforce on the interior surface of the cave or elastoplastic interface of the surrounding rock is considered to be $0 \mathrm{kPa}$ for the full grouted non-prestressed anchor.

4.2. Attenuation Characteristics of Long-Term Strength of Rock Mass on the Elastic-Plastic Interface. After the tunnel excavation, there are two cases where the rock mass failure occurs under the effect of the support pressure maximum [33]: (1) rock mass quickly breaks down in a short time, while support pressure maximum is more than the instantaneous compressive strength of the rock mass; (2) although the support pressure maximum is lower than the instantaneous strength of the rock mass, the long-term strength of the rock mass decreases continuously along with time passing and the failure of the rock mass occurs until the long-term strength is lower than the support pressure maximum. Figure 8 shows the attenuation characteristic curve of the long-term strength of rock mass with time.

According to the Maxwell rheological model and the test results [29], the relaxation equation of surrounding rock on the elastic-plastic interface can be expressed as follows:

$$
\sigma_{c_{t}}=\sigma_{c_{0}} \exp \left(\frac{-a t}{b+t}\right)
$$

where $\sigma_{\mathcal{c}_{0}}$ and $\sigma_{c_{t}}$ are instantaneous compressive strength and the compressive strength at $t$ moment, respectively, and $a$ and $b$ are undetermined constants, whose value ranges are $a=0 \sim 3$ and $b=50 \sim 150$.

According to the relationship between the principal stress maximum and the principal stress minimum on the condition of rock triaxial compression, the triaxial instantaneous limit strength can be written as follows [33]: 


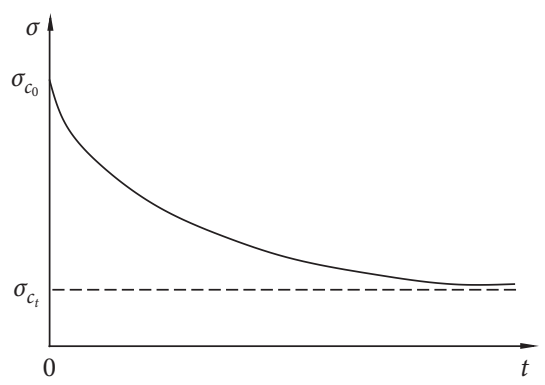

Figure 8: Relaxation curve of rock mass on the elastic-plastic interface.

$$
\sigma_{\text {tric }_{0}}=\frac{1+\sin \varphi}{1-\sin \varphi} \sigma_{r k}^{p}+\frac{2 c \cos \varphi}{1-\sin \varphi} .
$$

The compressive strength of the rock mass at any moment in case of triaxial compression could be inferred from equations (6) and (7):

$$
\sigma_{\text {trict }}=\left(\frac{1+\sin \varphi}{1-\sin \varphi} \sigma_{r k}^{p}+\frac{2 c \cos \varphi}{1-\sin \varphi}\right) \exp \left(\frac{-a t}{b+t}\right) .
$$

\subsection{Analysis of the Mechanics Criterion and Failure Moment of the Zonal Disintegration}

4.3.1. Mechanical Criterion of Zonal Disintegration. As previously mentioned, the transverse tensile deformation of the rock mass on the elastoplastic interface is only towards to the cave because of the free face on the cave wall or the exterior interface of the fractured zone. According to Griffith's strength theory, the rock mass deformation on the elastoplastic interface changes from a plastic state into a brittle radial crack state in the case that the tensile strain of the rock mass under the support pressure maximum reaches its ultimate value. The mechanics criterion of zonal disintegration can be established as follows [31]:

$$
\sigma_{r k}^{p}-\mu\left(\sigma_{\theta k}^{p}+\sigma_{z k}^{p}\right) \leq \sigma_{t}
$$

where $\sigma_{r k}^{P}$ is computed as

$$
\sigma_{r k}^{p}=\left(p_{k}-\sigma_{t}\right)\left(\frac{R_{p k}^{e}}{R_{s(k-1)}^{e}}\right)^{(2 \sin \varphi / 1-\sin \varphi)}+\sigma_{t},
$$

where $\sigma_{t}$ represents the tensile strength of surrounding rock, which can be obtained as follows:

$$
\sigma_{t}=-\frac{\sigma_{c}}{2}\left(\sqrt{m^{2}+4 s}-m\right) \text {. }
$$

In this section, $m$ is a coefficient related to the type and integrity of rock mass with $0.001 \leq m \leq 25$ and $s$ represents complete coefficient of rock mass with $0 \leq s \leq 1$.

$\sigma_{\theta k}^{p}$ and $\sigma_{z k}^{p}$ are obtained as follows:

$$
\left\{\begin{array}{l}
\sigma_{\theta k}^{p}=\frac{2}{1-\mu} P_{0}-\sigma_{r k}^{p}, \\
\sigma_{z k}^{p}=(1+2 \mu) P_{0} .
\end{array}\right.
$$

It can be seen from the above analysis that while the radial stress, tangential stress, and axial stress on the $(k+1)$ th elastic-plastic interface meet equation (9), the rock mass will produce cracking damage and develop into the $(k+1)$-th fractured zone under the effect of support pressure maximum.

4.3.2. Moment Analysis of the Zonal Disintegration. According to the intensity theory of deviatoric stress, the rock mass on the elastic-plastic interface will transform from a plastic state into a fractured state in the case that the deviatoric stress maximum between the tangential direction and radial direction is more than the long-term strength of the rock mass. The following equation can be obtained in line with equations (2) and (8):

$$
\left(\frac{1+\sin \varphi}{1-\sin \varphi} \sigma_{r k}^{p}+\frac{2 c \cos \varphi}{1-\sin \varphi}\right) \exp \left(\frac{-a t}{b+t}\right)=M .
$$

On the basis of equation (13), the formation moment of the $(k+1)$-th fractured zone on the elastic-plastic interface can be derived, as shown in the following equation:

$$
t_{k}=\frac{-b \cdot \ln \left(M / \sigma_{c 0}+(1+\sin \varphi / 1-\sin \varphi) \sigma_{r k}^{p}\right)}{a+\ln \left(M / \sigma_{c 0}+(1+\sin \varphi / 1-\sin \varphi) \sigma_{r k}^{p}\right)} .
$$

It is stressed that the compressive stress acting on the elastic-plastic interface is greater than its triaxial instantaneous limit strength, which leads to the break of the rock mass instantaneously in the case of $t_{k} \leq 0$.

\section{Analysis of Anchor Neutral Points in the Case of Zonal Disintegration}

5.1. Calculation Model of Bolt Neutral Points. For the convenience of analysis, this paper assumes the following: (1) non-prestressed full-length anchor bolts are used for the initial support of surrounding rock, and their length meets computational requirements; (2) there is no relative sliding between the bolt body and the surrounding rock that is homogeneous, continuous, and isotropic; and (3) the tensile strength of the surrounding rock is far below that of the bolt body. It takes the rock mass within the scope of $1 \mathrm{~m}$ along the axis of the cave as a research object.

The peak stress of surrounding rock transmits to the depth of surrounding rock continuously by multiple redistributions. The new neutral points appear constantly along the bolt body during the process of zonal disintegration of surrounding rock, the fractured zone with large deformation rate, and the nonfractured zone with low deformation rate on either side of it, as shown in Figure 9.

5.2. Analysis of Anchor Neutral Position. As can be seen from the mechanical model of the bolt body in Figure 9, under the condition of zonal disintegration, a set of frictional resistances of opposite direction and equal size acted on the bolt body within any zonal disintegration range, which is in static equilibrium. Therefore, the mechanical model of the 


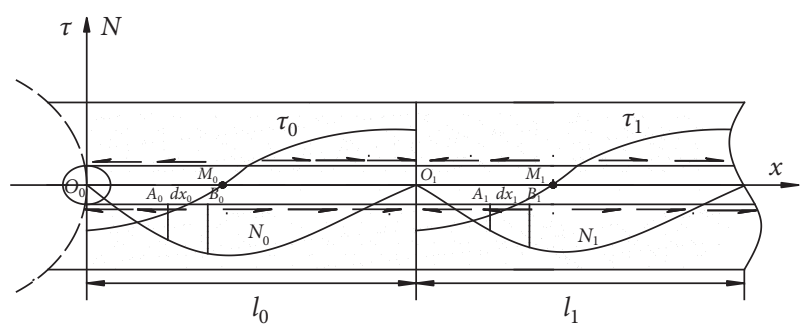

FIGURE 9: Mechanical model of the anchor bolt of zonal disintegration in deep underground cave.

$(k+1)$-th bolt body can be established, as demonstrated in Figure 10.

A microunit $A B$ of the bolt body in Figure 10 is taken as an analytic target which is at a distance of $x$ from the free face of the cave. The following equation can be derived:

$$
\frac{\mathrm{d} N_{x}}{\mathrm{~d} x}=U \tau_{x} .
$$

According to the theory of material mechanics [34], equation (16) can be derived:

$$
\left\{\begin{array}{l}
\mathrm{d} u_{x}=\varepsilon_{x} \mathrm{~d} x, \\
\varepsilon_{x}=\frac{\sigma_{x}}{E_{b}},
\end{array}\right.
$$

where $u_{x}$ and $\sigma_{x}$ as well as $\varepsilon_{x}$ are the displacement of the bolt body relative to surrounding rock and the stress as well as the strain of the rock mass and $E_{b}$ is the elasticity modulus of the bolt body, respectively.

The following can be obtained from equation (16):

$$
\varepsilon_{x}=\frac{\mathrm{d} u_{x}}{\mathrm{~d} x}=\frac{\sigma_{x}}{E_{b}}=\frac{N_{x}}{E_{b} A},
$$

where $A$ is the cross section area of the bolt body.

Therefore, by combining equations (15) and (17), the differential equation of the displacement can be derived as

$$
\frac{d^{2} u_{x}}{\mathrm{~d} x^{2}}=\frac{\mathrm{d} N_{x}}{E_{b} A d x}=\frac{U \tau_{x}}{E_{b} A}
$$

Based on Hooke's law, the relationship between shear stress and relative displacement may be expressed as follows:

$$
\tau_{x}=-K u_{x},
$$

where $K$ is the shear stiffness coefficient on the interface between the bolt body and surrounding rock.

According to equation (19), equation (18) can be further rewritten as

$$
\frac{\mathrm{d}^{2} u_{x}}{\mathrm{~d} x^{2}}+\frac{K U}{E_{b} A} u_{x}=0
$$

if

$$
\alpha_{1}=\sqrt{\frac{K U}{E_{b} A}} .
$$

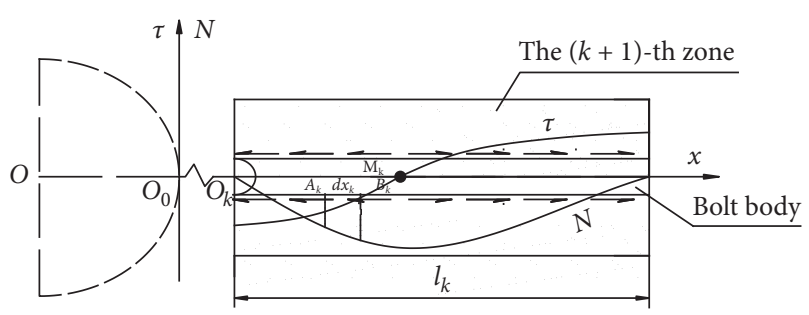

Figure 10: Mechanical model of neutral point on anchor bolt body.

Hence, equation (20) can be further rewritten as

$$
\frac{\mathrm{d}^{2} u_{x}}{\mathrm{~d} x^{2}}+\alpha_{1}^{2} u_{x}=0
$$

The characteristic equation of equation (22) can be shown as

$$
\lambda^{2}+\alpha_{1}^{2}=0
$$

where $\lambda$ is the characteristic root of equation (22), which can be written as

$$
\lambda= \pm \alpha_{1} \cdot \vec{i}
$$

It can be seen from equation (24) that the real part and imaginary part of the characteristic root are $\alpha=0$ and $\beta=\alpha_{1}$, respectively. Thus, the general solution of equation (22) can be expressed as

$$
u_{x}==c_{1} \cos \alpha_{1} x+c_{2} \sin \alpha_{1} x,
$$

where $c_{1}$ and $c_{2}$ are both undetermined coefficients.

According to Figure 9, the surrounding rock displacement and the axial force on the interior end of the bolt body can be determined as

$$
\left\{\begin{array}{l}
u_{x=0}=u_{0} \\
N_{x=0}=0
\end{array}\right.
$$

Combining equations (17), (25), and (26), the undetermined coefficients $c_{1}$ and $c_{2}$ can be written as

$$
\left\{\begin{array}{l}
c_{1}=u_{0} \\
c_{2}=0
\end{array}\right.
$$

Substituting equation (27) into (25), then

$$
u_{x}=u_{0} \cos \alpha_{1} x
$$

On the neutral point of the bolt body, the relative displacement between the surrounding rock and bolt body is zero, namely,

$$
u_{x}=u_{0} \cos \alpha_{1} x=0 .
$$

The solution to equation (29) can be written as

$$
O_{0} M_{k}=\frac{(2 k+1) \pi}{2 \alpha_{1}},
$$

where $k=0,1$, and 2 . 
Equation (30) clearly indicates that there are a few neutral points along the bolt body in the case of zonal disintegration.

\section{Range Determination of the Fractured Zone and Nonfractured Zone}

According to Figures 9 and 10, the mechanical model of the bolt body within any partition range of the surrounding rock can be established, as shown in Figure 11.

It can be seen from equation (30) and Figures 10 and 11 that the distance from any neutral point along the bolt body to the cave center can be expressed as

$$
\left\{\begin{array}{l}
O_{k} M_{k}=O_{0} M_{k}-\sum_{i=0}^{k-1} l_{i}, \cdots,(k \geq 1), \\
\rho_{k}=O_{k} M_{k}+R_{0}, \cdots,(k \geq 0) .
\end{array}\right.
$$

6.1. Calculation of Surrounding Rock Zone Width. In engineering practice, the bolt body moves along with the radial displacement of the surrounding rock. The surrounding rock and the bolt body deform in coordination within any partition range. At any distance $x$ from the free face of the cave, the relative displacement between the bolt and surrounding rock is defined as

$$
u_{x}=u_{b\left(x=O_{k} M_{k}\right)}-u_{r(x)},
$$

where $u_{r(x)}$ is the radial displacement of surrounding rock at any distance $x$ from the free face of the cave and $u_{b\left(x=O_{k} M_{k}\right)}$ is the radial displacement of the bolt body at any neutral point along the bolt body.

According to the theory of rock mass mechanics, the displacement of the surrounding rock at the neutral point can be calculated as

$$
u_{r\left(x=O_{k} M_{k}\right)}=\frac{B}{O_{k} M_{k}+R_{0}},
$$

where $B$ is a coefficient related to surrounding rock deformation, which is determined with the following formulation:

$$
B=\frac{(1+\mu)\left(R_{p 0}\right)^{2}}{E_{r}}\left(P_{0} \sin \varphi+c \cos \varphi\right),
$$

where $E_{r}$ and $\mu$ are the elasticity modulus and Poisson's ratio, respectively; $P_{0}$ is the stress of the primary rock before the excavation; and $R_{p_{0}}$ is the external diameter of the plastic zone while the secondary stress state of the surrounding rock has an elastic-plastic distribution that can be written as

$$
R_{p_{0}}=R_{0}\left[\frac{\left(P_{0}+c \cot \varphi\right)(1-\sin \varphi)}{c \cot \varphi}\right]^{(1-\sin \varphi / 2 \sin \varphi)} .
$$

The surrounding rock and bolt body deform coordinately after the surrounding rock is supported by the bolt. According to the properties of the neutral point of the bolt, it

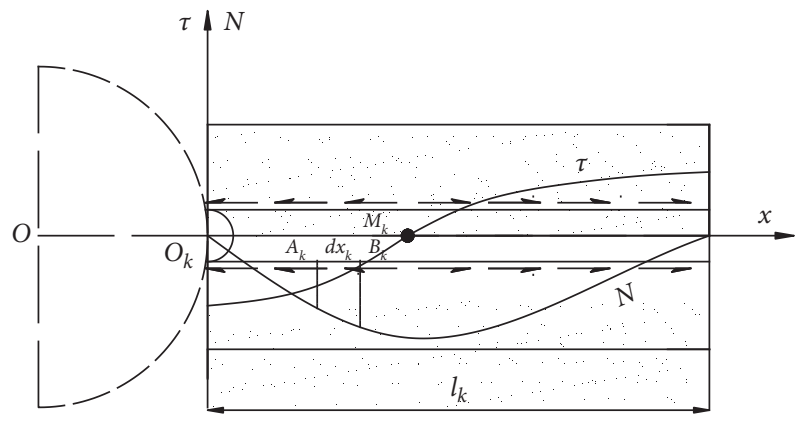

FIgURE 11: Computational model of the zonal thickness of surrounding rock.

can be seen that the displacement of the bolt body is equal to that of surrounding rock, namely,

$$
u_{b\left(x=O_{k} M_{k}\right)}=u_{r\left(x=O_{k} M_{k}\right)}=\frac{B}{O_{k} M_{k}+R_{0}} .
$$

The displacement of the surrounding rock at optional position is expressed as

$$
u_{r}=\frac{B}{r},
$$

where $r$ is the distance from the optional position to the cave center.

The shear force on the one side of the neutral point is equal to that on the other side of the neutral point; that is to say, the sum of the shear along the length $l_{k}$ of the partition bolt is zero, and therefore,

$$
\int_{R_{0}}^{R_{0}+l_{k}} \tau_{x} \mathrm{~d} r=0
$$

Ignoring the elongation of the bolt itself and substituting equations (19) and (33) as well as (9)-(37) into equation (38) yields

$$
\int_{R_{0}}^{R_{0}+l_{k}} K B\left(\frac{1}{O_{k} M_{k}+R_{0}}-\frac{1}{r}\right) \mathrm{d} r=0 .
$$

Equation (40) about the radius of neutral point and surrounding rock partition width can be deduced from equation (39):

$$
\rho_{k}=O_{k} M_{k}+R_{0}=\frac{l_{k}}{\ln \left(l_{k}+R_{0} / R_{0}\right)} .
$$

Therefore, the parameter $l_{k}$, that is, the $(k+1)$-th partition range of the surrounding rock, can be inferred from equations (31) and (40).

6.2. Analysis of the Width of the Fractured Zone and Nonfractured Zone of the Surrounding Rock. Figure 12 shows the width calculation model of the surrounding rock under the condition of zonal disintegration. Thereinto, $R_{s k}^{e}$ and $R_{p k}^{e}$ are the relative external diameters of the $(k+1)$-th fractured zone and nonfractured zone, respectively. 


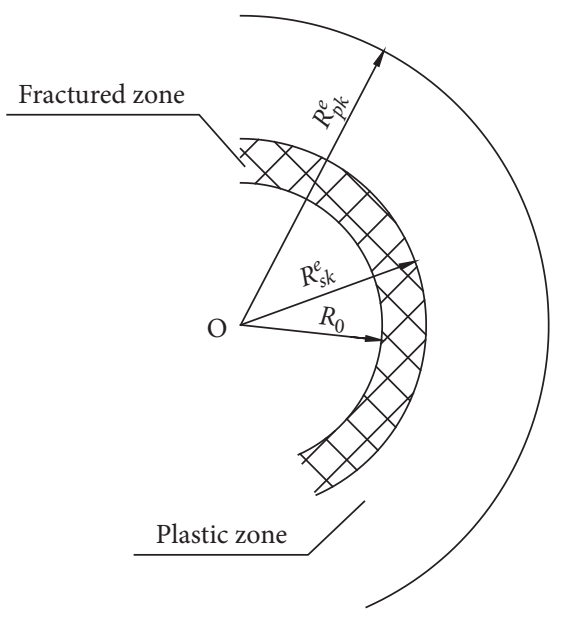

FIgURE 12: The relative outer diameter range of the $(k+1)$-th fractured zone and plastic zone in the surrounding rock.

6.2.1. Analysis for Determining the Relative External Diameter of the Nonfractured Zone. When the surrounding rock is reinforced by full-length anchor bolts, the stress acted on the nonfractured zone meets the Molar-Coulomb plastic equation, that is,

$$
\left\{\begin{array}{l}
\frac{\partial \sigma_{r k}^{p}}{\partial r}+\frac{\sigma_{r k}^{p}-\sigma_{\theta k}^{p}}{r}=0 \\
\frac{\sigma_{r}^{p}+c \cot \varphi}{\sigma_{\theta}^{p}+c \cot \varphi}=\frac{1+\sin \varphi}{1-\sin \varphi}
\end{array}\right.
$$

where $P$ is the component of the nonfractured zone.

Then, equation (42) can be inferred as

$$
\ln \left(\sigma_{r}^{p}+c \cot \varphi\right)=\frac{2 \sin \varphi}{1-\sin \varphi} \ln r+C_{0},
$$

where $C_{0}$ is an integral constant which is computed by equation (43):

$$
C_{0}=\ln \left(p_{k}+c \cdot \cot \varphi\right)-\frac{2 \sin \varphi}{1-\sin \varphi} \ln R_{0} .
$$

According to equations (41)-(43), the surrounding rock stress in the plastic zone can be deduced as

$$
\begin{aligned}
\sigma_{r k}^{P} & =\left(p_{k}+c \cdot \cot \varphi\right)\left(\frac{r}{R_{0}}\right)^{(2 \sin \varphi / 1-\sin \varphi)}-c \cdot \cot \varphi, \\
\sigma_{\theta k}^{P} & =\left(p_{k}+c \cdot \cot \varphi\right)\left(\frac{1+\sin \varphi}{1-\sin \varphi}\right)\left(\frac{r}{R_{0}}\right)^{(2 \sin \varphi / 1-\sin \varphi)}-c \cdot \cot \varphi,
\end{aligned}
$$

where $p_{k}$ is zero for the non-prestressed full-length anchor bolt.

Due to the coordinated deformation between the bolt body and surrounding rock, the displacement of the any unit along the full-length anchor bolt can be written as follows $[30,35]$ :

$$
u_{r}^{a}=\left[\frac{M\left(R_{0}^{a}\right)^{2}}{4 G}-R_{0} u_{0}^{b}\right] \frac{1}{r},
$$

where $G$ is the shear modulus of surrounding rock that is computed as

$$
G=\frac{E_{r}}{2(1+\mu)}
$$

The axial force of the bolt body at the free face of the cave is zero and, in the case of $R_{0} \leq r \leq \rho_{k}$, is expressed as

$$
\begin{aligned}
N_{1 k} & =-\int\left[\frac{M\left(R_{0}^{a}\right)^{2}}{4 G}-R_{0} u_{0}^{a}\right] E_{b} A\left(\frac{\mathrm{d}^{2}(1 / r)}{\mathrm{d} r^{2}}\right) \mathrm{d} r+C \\
& =\left[\frac{M\left(R_{0}^{a}\right)^{2}}{4 G}-R_{0} u_{0}^{a}\right] E_{b} A\left(\frac{1}{r^{2}}\right)+C,
\end{aligned}
$$

where $C$ is an integration constant which is determined by

$$
C=\left[\frac{M\left(R_{0}^{a}\right)^{2}}{4 G}-R_{0} u_{0}^{a}\right] E_{b} A \frac{1}{R_{0}^{2}} .
$$

Substituting equations (48) into (47), we get

$$
N_{1 k}=\left[\frac{M\left(R_{0}^{a}\right)^{2}}{4 G}-R_{0} u_{0}^{a}\right] E_{b} A\left(\frac{1}{R_{0}^{2}}-\frac{1}{r^{2}}\right) .
$$

In a similar way, under the condition of $\rho_{k}<r<r_{b k}$, the axial force of the bolt body is ascertained as follows:

$$
N_{2 k}=\left[\frac{M\left(R_{0}^{a}\right)^{2}}{4 G}-R_{0} u_{0}^{a}\right] E_{b} A\left(\frac{1}{R_{0}^{2}}-\frac{1}{r_{b k}^{2}}\right),
$$

where $r_{b k}$ is the distance between the right end of the bolt and the center of the tunnel within the range of each surrounding rock partition and is calculated by the following formula:

$$
r_{b k}=l_{k}+R_{0}
$$

In the case of $r=\rho_{k}$, equation (49) is equal to equation (50), from which the radius of the neutral point can be derived as follows:

$$
\rho_{k}=\sqrt{\frac{2 r_{b k}^{2} R_{0}^{2}}{R_{0}^{2}+r_{b k}^{2}}}
$$

At the neutral point, the axial force of the bolt body reaches its maximum, that is,

$$
N_{\max k}=\frac{b}{2}\left[\frac{M\left(R_{p k}\right)^{2}}{4 G}-R_{0} u_{0}^{b}\right] E_{b} A\left(\frac{1}{R_{0}^{2}}-\frac{1}{r_{b k}^{2}}\right),
$$

where $b$ is a coefficient about bolt spacing and lithology and $b<1, u_{0}^{b}$ is the initial displacement of the free face of the cave, $R_{p k}$ is the relative outer diameter of the nonfractured zone, and $r_{b k}$ is the distance from the external end of the bolt body to the cave center. 
While the surrounding rock stress redistributed $(k+2)$-th, the surrounding rock turns from a nonfractured into a fractured state on the condition that the transverse tensile strain of the rock mass on the elastoplastic interface exceeds its ultimate tensile strain. Then, the supporting pressure is transferred to the depth of surrounding rock. On the basis of equations (2) and (53), the relative external diameter of the $(k+1)$-th nonfractured zone can be derived as follows [30]:

$$
R_{p k}^{e}=\left(\frac{A_{k} R_{0}^{t}}{t \cdot\left(p_{k}+c \cdot \cot \varphi\right)}\right)^{(1 / t+2)},
$$

where $A_{k}$ and $t$ are determined as follows:

$$
\begin{aligned}
A_{k} & =4 G\left[\frac{2 N_{\max k}}{\left.b E_{b} A\left(\left(1 / R_{0}^{2}\right)\right)-\left(1 / r_{b k}^{2}\right)\right)}+R_{0} u_{0}^{b}\right], \\
t & =\frac{2 \sin \varphi}{1-\sin \varphi} .
\end{aligned}
$$

The axial force maximum at the neutral point of the bolt body can be computed by the following equation [28]:

$$
N_{\max k}=\operatorname{KUB}\left(\ln \frac{\rho_{k}}{R_{0}}+\frac{R_{0}}{\rho_{k}}-1\right) \text {. }
$$

Therefore, the relative external diameter of the $(k+1)$-th nonfractured zone can be obtained from equations (54)-(57).

6.2.2. Analysis for Determining the Relative External Diameter of the Fractured Zone. If the stress acted on the elastoplastic interface of the surrounding rock meets the condition illustrated in equation (9), the rock mass will turn from a plastic state into a brittle fractured state and develop into the $(k+1)$-th fractured zone, in which the relative external diameter is calculated with the following formulation:

$$
R_{s k}^{e}=R_{p k}^{e}\left(\frac{1}{1+\sin \varphi}\right)^{(1 / \mathrm{t})}
$$

Substituting equations (54) into (58) leads to

$$
R_{s k}^{e}=\left[\frac{A_{k} R_{0}^{t}}{t\left(p_{k}+c \cot \varphi\right)}\right]^{(1 / t+2)}\left(\frac{1}{1+\sin \varphi}\right)^{(1 / t)}
$$

In conclusion, the width of the $(k+1)$-th fractured zone and the $(k+1)$-th nonfractured zone may be evaluated as

$$
\left\{\begin{array}{l}
d_{s k}=R_{s k}^{e}-R_{0}, \\
d_{n s k}=l_{k}-d_{s k}
\end{array}\right.
$$

where $d_{s k}$ and $d_{n s k}$ are the width of the $(k+1)$-th fractured zone and the $(k+1)$-th nonfractured zone, respectively.

\section{Example Analysis}

7.1. Case Description. The proposed approach is applied in a water diversion tunnel, which has a total length of $81.78 \mathrm{~km}$, located in the Qinling mountain area of Shaanxi Province. The depth range of the tunnel is from 500 to $2000 \mathrm{~m}$, and its average buried depth is up to $912 \mathrm{~m}$. Within the mileage of $\mathrm{K} 45+180 \sim \mathrm{K} 45+370$, the surrounding rock is very weak and liable to large plastic deformation, rock spalling, and constriction which lead to difficulties in the tunnel construction. The design parameters, physical and mechanical parameters of surrounding rock, and anchoring parameters of the tunnel are shown in Tables 1 and 2.

According to the data presented in Tables 1 and 2, each zonal width of surrounding rock in this engineering can be calculated by equations (31), (40), and (60). The radial stress, tangential stress, and axial stress on the elastic-plastic interface obtained from equations (10) and (12) are substituted into equation (9), and the stability of the elastoplastic interfacial rock mass may be discriminated. The quantity of zonal disintegration is demonstrated in Table 3.

Table 3 shows that equation (9) is false in the case of $k=4$. Therefore, there are four fractured zones existing in the surrounding rock of the water diversion tunnel.

Based on equation (35), the external diameter of the plastic zone on the condition of elastoplastic state is $2.12 \mathrm{~m}$ before the surrounding rock is anchored. According to equations (54), (57), (58), and (60), the parameters such as $R_{p}^{e}, N_{\max }, R_{s}^{e}, d_{s}$, and $d_{n s}$ can be derived. For this project, the full grouted non-prestressed anchor is adopted, for which the support counterforce is considered to be $0 \mathrm{kPa}$, and then, the parameter $M$, that is, the deflection stress maximum, can be calculated by equation (2). Furthermore, the creep rupture moment of the rock mass on each elastoplastic interface can be derived by equation (14), as shown in Table 4.

Combining the distribution situation of zonal disintegration in Table 3 and fractured moment listed in Table 4, the time-space distribution law of zonal disintegration about this cave is shown in Table 5 and Figure 13.

7.2. Verification. In order to verify the reliability of the above theoretical calculation results, the TYGD10 television imager for rock drilling was used to monitor the fracture development of surrounding rock on-site. The distribution of partial typical fractures in deep surrounding rock is demonstrated in Figure 14.

The above analysis found that there are four fractured zones generated in the surrounding rock of this tunnel, with further details as follows. The first serious fractured zone can be considered as the traditional loose zone that ranges from 0.0 to $0.42 \mathrm{~m}$ and outside of which is the first nonfractured zone. As for the second fractured zone, the width of which is from 5.18 to $5.53 \mathrm{~m}$, the damage degree of the rock mass within this range is relatively serious, and the next is the second nonfractured. The failure mode of the third fractured zone with a width range from 6.95 to $7.41 \mathrm{~m}$ mainly performs cracks. Last, next to the third nonfractured zone is the fissured fourth fractured zone, with a width range from 10.83 to $11.05 \mathrm{~m}$. The comparison between theoretical calculation results and field measurement values of zonal disintegration is shown in Table 6. 
TABLE 1: Calculation parameter values of the Qinling water diversion tunnel.

\begin{tabular}{lccccc}
\hline Parameters & $R_{0}(\mathrm{~m})$ & $\mu$ & $\sigma_{c}(\mathrm{MPa})$ & $P_{0}(\mathrm{MPa})$ & 22.8 \\
\hline Value & 2.0 & 0.25 & 37.7 & $\varphi_{0}(o)$ \\
Parameters & $E_{r}(\mathrm{GPa})$ & $\tau_{p}(\mathrm{MPa})$ & $l_{0}\left(t_{0}\right)(\mathrm{m})$ & $c_{0}(\mathrm{MPa})$ & 15 \\
Value & 4.2 & 48 & 0.03 & $\sigma_{t}(\mathrm{MPa})$ & 2.5 \\
Parameters & $b$ & $\tau_{s}(\mathrm{MPa})$ & 36.72 & - \\
Value & 50 & 36 & - & 1.68 \\
\hline
\end{tabular}

TABLE 2: Calculation parameter values of the bolt.

\begin{tabular}{lccccc}
\hline Parameters & $U(\mathrm{~m})$ & $A(\mathrm{~m})$ & $k$ & $K(\mathrm{MPa} / \mathrm{m})$ & $E_{b}(\mathrm{GPa})$ \\
\hline Value & 0.08 & $4.91 \times 10^{-4}$ & 0.8 & 22.8 & 40 \\
\hline
\end{tabular}

TABLE 3: Stability analysis results of the Qinling water diversion tunnel.

\begin{tabular}{ccccccccccc}
\hline$k$ & $\alpha_{1}\left(\mathrm{~m}^{-1}\right)$ & $O_{0} M_{k}(\mathrm{~m})$ & $O_{k} M_{k}(\mathrm{~m})$ & $\rho_{0}(\mathrm{~m})$ & $l_{0}(\mathrm{~m})$ & $\sigma_{r_{0}}(\mathrm{MPa})$ & $\sigma_{\theta_{0}}(\mathrm{MPa})$ & $\sigma_{z_{0}}(\mathrm{MPa})$ & $\mid$ Equation $(9) \mid(\mathrm{MPa})$ & Whether or not broken \\
\hline 0 & 1.21 & 1.29 & 1.29 & 3.3 & 3.07 & -35.55 & 96.35 & 34.2 & $68.18>36.72$ & Yes \\
1 & 1.21 & 3.89 & 0.82 & 2.82 & 1.84 & -98.69 & 159.49 & 34.2 & $147.12>36.72$ & Yes \\
2 & 1.21 & 6.48 & 1.57 & 3.57 & 3.83 & -30.83 & 91.63 & 34.2 & $62.29>36.72$ & Yes \\
3 & 1.21 & 9.08 & 0.34 & 2.34 & 0.69 & -32.56 & 93.36 & 34.2 & $62.45>36.72$ & Yes \\
4 & 1.21 & 1.68 & 2.25 & 4.25 & 5.77 & -10.29 & 71.09 & 34.2 & $36.61<36.72$ & No \\
\hline
\end{tabular}

TABLE 4: Calculation results of creep fracture moment of the Qinling water diversion tunnel.

\begin{tabular}{ccccccccc}
\hline$k$ & $N_{\max }(\mathrm{kN})$ & $A_{0}$ & $R_{p}^{e}(\mathrm{~m})$ & $R_{s}^{e}(\mathrm{~m})$ & $d_{s}(\mathrm{~m})$ & $d_{n s}(\mathrm{~m})$ & $M(\mathrm{MPa})$ & $t_{k}(\mathrm{~d})$ \\
\hline 0 & 83 & $7.4 \times 10^{8}$ & 3.17 & 2.49 & 0.49 & 2.58 & 73.8 \\
1 & 41 & $5.9 \times 10^{8}$ & 6.05 & 5.41 & 0.34 & 1.50 & 13.4 \\
2 & 108 & $8.2 \times 10^{8}$ & 8.19 & 7.48 & 0.57 & 3.26 & 69.7 \\
3 & 9 & $4.7 \times 10^{8}$ & 11.52 & 10.93 & 0.19 & 0.50 & 19.9 \\
\hline
\end{tabular}

TABLE 5: Calculation results of zonal disintegration in Qinling water diversion tunnel.

\begin{tabular}{ccccccc}
\hline$k$ & $\begin{array}{c}\text { Zonal } \\
\text { width }(\mathrm{m})\end{array}$ & $\begin{array}{c}\text { Outer diameter } \\
\text { fractured zone }(\mathrm{m})\end{array}$ & $\begin{array}{c}\text { Width of } \\
\text { fractured zone }(\mathrm{m})\end{array}$ & $\begin{array}{c}\text { Outer diameter of } \\
\text { nonfractured zone }(\mathrm{m})\end{array}$ & $\begin{array}{c}\text { Width of nonfractured } \\
\text { zone }(\mathrm{m})\end{array}$ & $\begin{array}{c}\text { Breakdown moment } \\
\text { of the zonal disintegration }(\mathrm{d})\end{array}$ \\
\hline 0 & 3.07 & 2.49 & 0.49 & 5.07 & 2.58 & 13.4 \\
1 & 1.84 & 5.41 & 0.34 & 6.91 & 1.50 & 19.9 \\
2 & 3.83 & 7.48 & 0.57 & 10.74 & 3.26 & 12.5 \\
3 & 0.69 & 10.93 & 0.19 & 11.43 & 0.50 & 12.8 \\
\hline
\end{tabular}

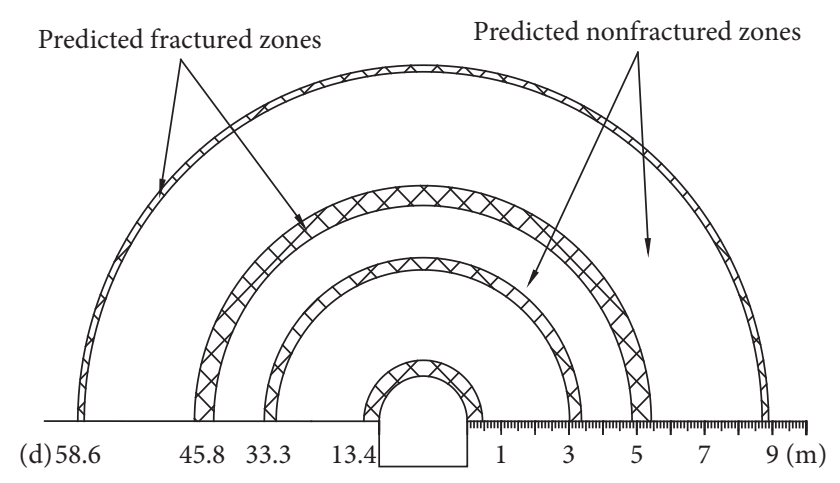

FIgURE 13: Distribution law of zonal disintegration in Qinling water diversion tunnel. 


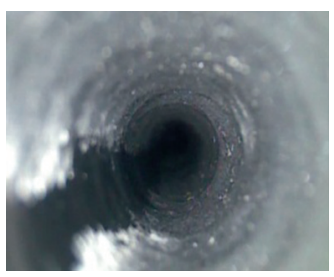

(a)

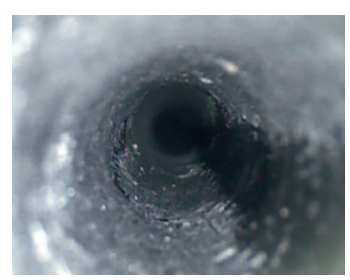

(b)

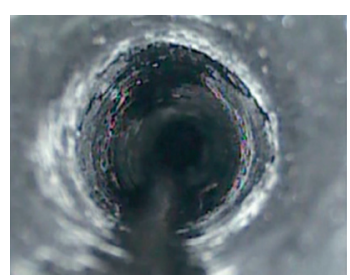

(c)

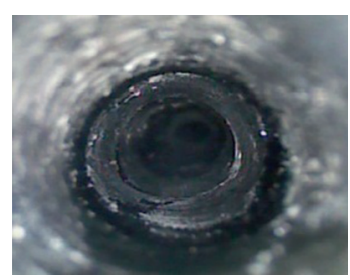

(d)

Figure 14: Field monitoring results of fracture distribution in partial deep rock mass: (a) $0.56 \mathrm{~m}$; (b) $5.3 \mathrm{~m}$; (c) $7.1 \mathrm{~m}$; (d) $10.8 \mathrm{~m}$.

TABLE 6: Comparison of theoretical calculation and field measurement of zonal disintegration in Qinling water diversion tunnel.

\begin{tabular}{ccccc}
\hline & Zonal diameter $(\mathrm{m})$ & Field monitoring $(\mathrm{m})$ & Calculation result $(\mathrm{m})$ & \\
\hline \multirow{2}{*}{0} & Inner diameter & 2.00 & 2.00 & Error $(\%)$ \\
\hline \multirow{2}{*}{1} & Outer diameter & 2.42 & 2.49 & \multirow{2}{*}{16.7} \\
\hline \multirow{2}{*}{2} & Inner diameter & 5.18 & 5.07 & -2.9 \\
\hline \multirow{2}{*}{3} & Outer diameter & 5.53 & 6.91 & 7.48 \\
& Inner diameter & 6.95 & 10.74 \\
\multirow{2}{*}{ Outer diameter } & 7.41 & 10.93 \\
\hline
\end{tabular}

Based on the determination of the location, thickness, and fractured moment of the zonal disintegration in this tunnel, reasonable optimization about the original support scheme as well as its relevant parameters will be discussed in another paper due to the space limitation of the present paper.

\section{Conclusions}

This study presents the applicability of revealing the spacetime evolution laws based on the mechanical model and principle of coordinated deformation of interaction between anchor and surrounding rock. Both the stress distribution rules of the same bolt body at different moments and that of different bolt bodies at the same time in the case of zonal disintegration are discussed in detail. The results of this study indicate that, with the nonlinear rheological mechanics model of rock mass on the elastic-plastic interface and the stress distribution laws of the bolt body, the rupture moment and location, the width, and the quantities of each fractured zone can be accurately predicted. Specific conclusions are listed as follows:

(1) The surrounding rock stress will be redistributed repeatedly after excavation of a deep cave. Due to the remarkable rheological properties of rock mass, the long-term strength of the rock mass constantly decreases with time passing. While the tensile stress of the rock mass on the elastic-plastic interface reaches its ultimate tensile stress, the surrounding rock may come into zonal disintegration.

(2) The stress and strain of surrounding rock at different depths have the distribution characteristics of tension and pressure alternation after zonal disintegration occurs. Because of the coordinated deformation between the bolt and surrounding rock, multiple groups of opposing frictional resistance and neutral points without relative displacements exist along the bolt body. According to the mechanical model of the bolt in the case of zonal disintegration and neutral point theory of the bolt body, the location and the width of each fractured zone may be analyzed inversely.

(3) The zonal disintegration of surrounding rock not only has the objective natural law of fractured zone and nonfractured zone alternate distribution but also is a progressive destruction process closely related to time. The mechanics criterion and the specific time required for the rock mass on the elastic-plastic interface to take the shape of the fractured zone can be ascertained by the nonlinear rheological mechanics model under the maximum support pressure.

(4) In fact, it is easy to determine the excavation scheme and its surrounding rock support parameters of a deep-buried rock mass engineering. The special zonal disintegration behavior of surrounding rock can be determined by the value of the anchor rod pretightening force. Therefore, it is possible to prevent the occurrence of zonal disintegration of surrounding rock by determining reasonable bolt parameters, which is in order to provide reliable technical support for the rapid construction and safe operation for deep-buried rock mass engineering [36-41]. 


\section{Symbols}

$\sigma_{r k}^{P}: \quad$ Radial horizontal stress on the $(k+1)$-th elastoplastic interface of surrounding rock

$\sigma_{z k}^{P}: \quad$ Tangential vertical stress on the $(k+1)$-th

$\sigma_{\theta k}^{P}:$

M:

$R_{s(k-1)}^{e}$ :

$R_{p k}^{e}$ :

$R_{0}$ :

$c_{0}$ :

$\varphi_{0}$ :

$R_{s(k-1)}^{i}$ :

$\tau_{s}:$

$\tau_{p}$ :

$p_{k}$ :

$\sigma_{c_{0}}:$

$\sigma_{c_{t}}$ :

$\sigma_{\text {trict }}:$

$\sigma_{t}:$

$t_{k}$ :

$N_{x}$ :

$\tau_{x}$ :

$u(r)$ :

$u_{x}$ :

$\sigma_{x}:$

$\varepsilon_{x}$ :

A:

$E_{b}$ :

$K$ :

$\rho_{k}$ :

$u_{r(x)}$ :

$u_{b\left(x=O_{k} M_{k}\right)}$

$B:$

$E_{r}$ :

$\mu$ :

$R_{p_{0}}$ :

$r:$

$l_{k}$ : The $(k+1)$-th partition range of the

$R_{s k}^{e}$ :

$R_{p k}^{e}$ : elastoplastic interface of surrounding rock Axial horizontal stress on the $(k+1)$-th elastoplastic interface of surrounding rock Deviatoric stress on the elastoplastic interface Outer diameter of the $k$-th fractured zone of the surrounding rock

The $(k+1)$-th plastic zone outer diameter Design excavation radius Initial cohesive force of rock mass Initial internal friction angle of rock mass Inner diameter of the $k$-th fractured zone of the surrounding rock

Residual shear strength of surrounding rock Maximum of the shear strength

Support reverse force acted on the free face of the cave

Instantaneous compressive strength of surrounding rock

\section{Compressive strength at $t$ time}

Compressive strength of rock mass at any moment

Tensile strength of surrounding rock Formation time of the $(k+1)$-th fractured zone on the elastic-plastic interface

\section{Axial force}

\section{Shear stress}

Cross-sectional perimeter of bolt body

Relative displacement between the surrounding rock and bolt body

Stress of rock mass

Strain of rock mass

Cross-sectional area of the bolt body

Elasticity modulus of the bolt body

Shear stiffness coefficient on the interface between the bolt body and surrounding rock

Distance from any neutral point along the bolt body to the cave center

Radial displacement of surrounding rock at any distance $x$ from the free face of the cave

: Radial displacement of the bolt body at any neutral point along the bolt body

: A coefficient related to surrounding rock deformation

: Elasticity modulus of the rock mass

Poisson's ratio of the surrounding rock

External diameter of the plastic zone

Distance from the optional position to the cave center surrounding rock

sk $\quad$ Relative external diameters of the $(k+1)$-th fractured zone

Relative external diameters of the $(k+1)$-th nonfractured zone

$C_{0}: \quad$ An integral constant

$G$ : $\quad$ Shear modulus of surrounding rock

$r_{b k}$ : Distance between the right end of the bolt and

the center of the tunnel

$N_{\text {max }}$ : $\quad$ Maximum axial force of the bolt body

$u_{0}^{b}$ : $\quad$ Initial displacement of the free face of the cave

$d_{s k}$ : Width of the $(k+1)$-th fractured zone

$d_{n s k}: \quad$ The $(k+1)$-th nonfractured zone.

\section{Data Availability}

All data and models generated or used during the study appear in the submitted article. Some data on the engineering example are provided by the manager department of the diversion tunnel project, which is from Hanjiang to Weihe River in Qingling mountain area affiliated to China Railway Tunnel Stock Co., Ltd.

\section{Conflicts of Interest}

The authors declare that they have no conflicts of interest.

\section{Acknowledgments}

This research was supported by the Natural Science Foundation Research Project of Shaanxi Province (2014JM25052), the Doctor Start-Up Financial Fund of Xi'an University of Science and Technology (2014QDJ049), and China Postdoctoral Science Foundation (2015M582761XB). The authors are thankful to the manager department of the diversion tunnel project, which is from Hanjiang to Weihe River in Qingling mountain area affiliated to China Railway Tunnel Stock Co., Ltd.

\section{References}

[1] H. P. Xie, F. Gao, and Y. Ju, "Research and development of rock mechanics in deep ground engineering," Chinese Journal of Rock Mechanics and Engineering, vol. 34, no. 11, pp. 2161-2178, 2015.

[2] H. P. Xie, "Research framework and anticipated results of deep rock mechanics and mining theory," Advanced Engineering Scuences, vol. 49, no. 2, pp. 1-16, 2017.

[3] Z. L. Fang, "Support principles for roadway in soft rock and its controlling measures," in Soft Rock Tunnel Support in Chinese Mines: Theory and Practice, H. E. Manchao, Ed., China Coal Industry Publishing House, Beijing, China, 1996.

[4] Е. И. ШЕМЯКИН, М. В. КУРЛЕНЯ, and В. Н. ОШАРИН, “Зональная дезинтеГрация Горныч Шород вокруГ Шодземныч выработок часть III," теоретические Шредставления. ФТШРШИ, vol. 1, pp. 3-8, 1987.

[5] М. А. ГУЗЕВ and В. Ш. МЯСНИКОВ, "Термомечаническая модель уШруГоШластическоГо материала с дефектами структуры," Мечаника твериала твердоГо тела, nо. 4, pp. 156-172, 1998.

[6] L. S. Metlov, A. F. Morozov, and M. P. Zborshchik, "Physical foundations of mechanism of zonal rock failure in the vicinity of mine working," Journal of Mining Science, vol. 38, no. 2, pp. 150-155, 2002. 
[7] V. E. Mirenkov, "Zonal disintegration of rock mass around an underground excavation," Journal of Mining Science, vol. 50, no. 1, pp. 33-37, 2014.

[8] C. Z. Qi, K. R. Li, J. P. Bai, A. I. Chanyshev, and P. Liu, "Strain gradient model of zonal disintegration of rock mass near deep-level tunnels," Journal of Mining Science, vol. 53, no. 1, pp. 21-33, 2017.

[9] S. P. Bai, "Observation of coal roadway roof bolt tests at 3109 mechanized section at quantai mine: charaterstics of coal roadway roof bolts and new viewpoints on the choice of roof bolt parameters," Journal of China University of Mining \& Technology, vol. 4, pp. 19-57, 1979.

[10] Q. H. Qian, "The characteristic scientific phenomena of engineering response to deep rock mass and the implication of deepness," Journal of East China Institute of Technology, vol. 27, no. 1, pp. 1-5, 2004.

[11] J. C. Gu, "Model test study on mechanism of layered fracture within surrounding rock of tunnels in deep stratum," Chinese Journal of Rock Mechanics \& Engineering, vol. 27, no. 3, pp. 433-438, 2008.

[12] C. R. Li, L. J. Kang, and Q. X. Qi, "Probe into relationship between zonal fracturing and rock burst in deep tunnel," Journal of China Coal Society, vol. 35, no. 2, pp. 185-189, 2010.

[13] X. P. Zhou, J. Bi, and Q. H. Qian, "The zonal disintegration mechanism of isotropic rock masses around a deep circular tunnel subjeccted to dynamic unloading," Chinese Journal of Solid Mechanics, vol. 34, no. 4, pp. 352-360, 2013.

[14] J. R. Lu, "Mechanism of zonal disintegration within surrounding rock of deep tunnel based on 3D analytical model of thick-walled cylinder," Yantu Lixue/Rock and Soil Mechanics, vol. 35, no. 9, pp. 2673-2684, 2014.

[15] X. G. Zhu, Z. L. Chen, and D. S. Zhao, "Analysis of the stress/ strain wall rock anddiscussion of its fracture mechanics in deep tunnel," Journalof Xi'an Yniversity of Technology, vol. 33, no. 4, pp. 402-407+485, 2017.

[16] X. G. Chen and Q. Y. Zhang, "Mechanism analysis of phenomenon of zonal disintegration in deep tunnel model test under high geostress," Rock and Soil Mechanics, vol. 32, no. 1, pp. 84-89, 2011.

[17] Z. J. Su and Q. H. Qian, "Numerical simulation research on zonal disintegration phenomenon of rock mass around deep grotto," Journal of Wuhan University of Technology, vol. 36, no. 2, pp. 89-94, 2014.

[18] X. T. Zhang, "The research on failure mechanism and mumerical simulation analysis of zonal disintegration in deep tunnel," Dissertation, Shandong University, Jinan, China, 2015.

[19] Y. Pan, A. W. Li, and Y. S. Qi, "Analysis and illustration on deviatoric stress strain energy generation of surrounding rock in circuar tunnel excavation," Chinese Journal of Geotechnical Engineering, vol. 29, no. 12, pp. 1780-1786, 2007.

[20] Q. Y. Zhang, X. G. Chen, and B. Lin, "Study of 3d geomechanical model test of zonal disintegration of surrounding rock of deep tunnel," Chinese Journal of Rock Mechanics \& Engineering, vol. 28, no. 8, pp. 1757-1766, 2009.

[21] Q. Y. Zhang, X. T. Zhang, W. Xiang et al., "Model test study of zonal disintegration in deep rock mass under different cavern shapes and loading conditions," Chinese Journal of Rock Mechanics \& Engineering, vol. 32, no. 8, pp. 1564-1571, 2013.

[22] L. Yuan, J. C. Gu, J. H. Xue et al., "Model test research on the zonal disintegration in deep rock," Journal of China Coal Society, vol. 39, no. 6, pp. 987-993, 2014.
[23] М. В. КУРЛЕНЯ and В. Н. ОШАРИН, "К воШросу о факторе времени Шри разрушении Горныч Шород," vol. ФТШРШИ, no. 2, p. 33, 1993.

[24] Y. J. Li, Y. S. Pan, and Z. H. Li, "Analysis of mechanism of zonal disintegration of rocks," Chinese Journal of Geotechnical Engineering, vol. 28, no. 91, pp. 1124-1128, 2006.

[25] X. P. Zhou, Q. H. Qian, B. H. Zhang et al., "The mechanism of the zonal disntegration phenomenon around deep spherical tunnels," Engineering Mechanics, vol. 27, no. 1, pp. 69-90, 2010.

[26] Q. Qian and S. Li, "Review of research on zonal disintegration phenomenon in deep rock mass engineering," Chinese Journal of Rock Mechanics \& Engineering, vol. 27, no. 6, pp. 12781284, 2008.

[27] X. P. Zhou and Q. H. Qian, "Zonal fracturing mechanism in deep tunnel," Chinese Journal of Rock Mechanics and Engineering, vol. 26, no. 5, pp. 877-885, 2007.

[28] M. S. Wang, "Mechanism of full-column rock bolt," Journal of China Coal Society, no. 1, pp. 40-47, 1983.

[29] Y. M. Li, H. Zhang, and X. R. Meng, "Research on secondary support time of soft rock roadway," Journal of China Coal Society, vol. 40, no. 1, pp. 47-52, 2015.

[30] C. Wang, D. P. Xiao, J. Z. Wen et al., "Research on back calculation of plastic zone in surrounding rock from axial force of rock bolts," Journal of Chongqing Jiaotong University (Natural Science), vol. 28, no. 1, pp. 369-371, 2009.

[31] J. G. Chen, C. H. Zhu, and Y. X. Zhang, "Elastic-plastic-brittle analysis of zonal disintegration within rock mass in deep tunnel," Journal of China Coal Society, vol. 35, no. 4, pp. 541-545, 2010.

[32] G. M. Zhang, Y. P. Li, C. H. Yang et al., "Discussion on relationship between post-peak curves and shear strength parameters of rocks subjected to direct shear teats," Chinese Journal of Rock Mechanics and Engineering, vol. 31, no. 1, pp. 2981-2988, 2012.

[33] D. Q. Li and L. G. Wang, Large Scale Mining Theory and Technology for Deep Hard Rock-Research and Practice of Mining in the Dong Gua Shan Copper Mine, Metallurgical Industry Press, Beijing, China, 2009.

[34] X. F. Sun, X. S. Fang, and L. T. Guan, Mechanics of Materials(I), Higher Education Press, Beijing, China, 2009.

[35] G. C. Xu, H. C. Bai, Y. R. Zheng et al., "Underground engineering support structure," China Water Conservancy and Hydropower Press, Beijing, China, 2002.

[36] X. G. Chen, "Study on forming mechanism and anchorage character of zonal disintegration in rock mass of deep tunnel under high geostress," Dissertation, Shandong University, Jinan, China, 2011.

[37] H. U. She-Rong, "An overview of current status and progress in coal mining of the deep over a kilometer," Chinese Medical Journal, 2011.

[38] Y. S. Pan, "Study on zonal desintegration of rock," Chinese Journal of Rock Mechanics and Engineering, vol. 26, no. 1, pp. 3335-3341, 2007.

[39] E. I. Shemyakin and M. V. Kurlenya, "Zonal disintegration of rocks around underground workings, Part 1: data of in situ observations," Soviet Mining Science, vol. 22, no. 3, pp. 157-168, 1986.

[40] M. R. Fisenko, Rockmass Mechanics, Tongji University Press, Shanghai, China, 2002.

[41] H. P. Xie, Basic Theory and Engineering Practice of Deep Mining, Chin Science Publishing, Beijing, China, 2006. 